\title{
A SUBDETERMINAÇÃO SEMÂNTICA DA METÁFORA
}

\author{
The semantic underdetermination of metaphor \\ La subdeterminación semántica de la metáfora
}

Daniel Schiochett ${ }^{1}$

Universidade do Sul de Santa Catarina, Tubarão, SC, Brasil.

\section{Resumo}

Este trabalho pretende sustentar que o melhor conceito para tratar da relação entre metáfora e linguagem é o da subdeterminação semântica. Entretanto, o modo mais comum de tratar o fenômeno das metáforas relega à pragmática (e não à semântica, como era de se esperar) a função de explicar como o significado metafórico de uma frase é um acarretamento gerado pelo contexto. Segundo esse quadro, metáforas seriam indeterminadas semanticamente pois acarretamentos pragmáticos são virtualmente infinitos e não precisam remeter à proposição semanticamente expressa. Argumentamos, entretanto, que as melhores alternativas para o tratamento da questão nascem do debate entre o contextualismo e o minimalismo semânticos. Metáforas seriam casos de flexibilidade semântica também presentes em outros fenômenos linguísticos. Para o minimalismo, metáforas podem ser tratadas através da introdução de um operador lexical que garantiria a flexibilidade contextual necessária a termos semânticos contextualmente dependentes. Para o contextualismo, metáforas acontecem quando termos em uma frase funcionam como conceitos ad hoc e são passíveis de enriquecimentos pragmáticos. Apesar de não chegarem a uma solução única, o

Doutor em filosofia (ontologia) pela Universidade Federal de Santa Catarina (UFSC). Professor da Universidade do Sul de Santa Catarina (UNISUL). DOI: http://orcid.org/0000-0003-44988586. E-mail danielschiochett@gmail.com 
debate entre minimalismo e contextualismo oferece explicações do fenômeno que corroboram a hipótese da subdeterminação semântica defendida neste trabalho.

Palavras-chave: Metáfora. Subdeterminação semântica. Código linguístico. Minimalismo. Contextualismo.

\begin{abstract}
This work intends to sustain that the best concept to deal with the relationship between metaphor and language is the one of semantic underdetermination. However the most common way of dealing with the phenomenon of metaphors relegates to pragmatic (not to semantics as expected) the function of explaining how the metaphorical meaning of a phrase is a context-generated entailment. According to this picture, metaphors would be indeterminate semantically because pragmatic entailments are virtually infinite and do not need to refer to the semantically expressed proposition. We argue, however, that the best alternatives to handle with matter come from the debate between contextualism and semantic minimalism. Metaphors would be cases of semantic flexibility also present in other linguistic phenomena. For minimalism, metaphors can be addressed through the introduction of a lexical operator that would guarantee the necessary contextual flexibility to contextually dependent semantic terms. For contextualism, metaphors occur when terms within a phrase function as ad hoc concepts and are amenable to pragmatic enrichments. Although they do not reach a single solution, the debate between minimalism and contextualism offers explanations of the phenomenon that corroborate the hypothesis of the semantic underdetermination presented in this work.
\end{abstract}

Keywords: Metaphor. Semantic underdetermination. Linguistic code. Minimalism. Contextualism.

\title{
Resumen
}

Este trabajo tiene la intención de argumentar que el mejor concepto para abordar la relación entre la metáfora y lenguaje es el de la de subdeterminación de la semántica. Sin embargo, la forma más común para tratar con el fenómeno de las metáforas se relega a la pragmática ( y no a la semántica, como se podria esperar) la función para explicar cómo el significado metafórico de una oración es una vinculación generado por el contexto. Según este marco general, las metáforas serían indeterminadas semánticamente pues las implicaciones pragmáticas son virtualmente infinitas y no necesitan referirse a la proposición semánticamente expresada. Sostenemos, 
sin embargo, las mejores alternativas para el tratamiento de la cuestión nacen del debate entre el contextualismo y el minimalismo semántico. Metáforas serían casos de flexibilidad semántica también presentes en otros fenómenos lingüísticos. Para el minimalismo, metáforas pueden abordarse a través de la introducción de un operador lexical que garantice la flexibilidad contextual necesaria necesaria para términos semánticos contextualmente dependientes. Para el contextualismo, metáforas ocurren cuando términos en una frase funcionan como conceptos ad hoc y son pasibles de enriquecimientos pragmáticos. Aunque no llegan a una solución única, el debate entre minimalismo y contextualismo ofrece explicaciones del fenómeno que corroboran la hipótesis de la subdeterminación semántica defendida en este trabajo.

Palabras clave: Metáfora. Subdeterminação Semántica. Código linguístico. Minimalismo. Contextualismo.

"[...] se pensa no geral não com paixão, mas com uma tranquila superficialidade.

A exceção, ao contrário, pensa o geral com enérgica passionalidade".

(Kierkegaard)

\section{Introdução}

Muitos trabalhos surgiram nas últimas décadas sobre a metáfora. Destacamos o texto inaugural de Black (1962), as aulas de Grice de 1967 (2013), as discussões de Davidson (1978) e de Searle (1979), passando pelos estudos de Sperber e Wilson (1995), Lakoff e Johnson (1980) e, mais recentemente, os textos de Stern (2000, 2009), Reimer (2009) e Bezuidenhout (2001). Esse fenômeno, ao figurar no limite da significatividade, acaba servindo tanto àqueles que defendem uma visão mais dura quanto aqueles que defendem uma noção mais frouxa da significatividade linguística. A metáfora, assim como a "exceção" de que fala Kierkegaard, aparece no limiar da significação: aqueles que pensam a significatividade linguística a partir da letra do código linguístico, precisam pensar as metáforas como fenômenos que escapam à possibilidade de determinação 
semântica; aqueles que pensam a significatividade linguística a partir das determinações contextuais, não podem fugir das metáforas como fenômenos que mostram o poder do código linguístico na produção de significados. Assim, se for possível oferecer uma explicação satisfatória de como as metáforas funcionam poderemos optar por uma teoria mais contextualista ou mais semântica do significado.

Antes de entrar diretamente na discussão deste estudo, cabe tecer alguns comentários. A discussão sobre metáforas não é uma discussão sobre figuras de linguagem. Não pensamos a metáfora a partir de suas diferenças em relação às metonímias, catacreses, hipérboles ou ironias. Seguimos o fio da tradição que trata esse fenômeno como tratara o próprio Aristóteles que define a metáfora como "a transferência para uma coisa do nome de outra" (Poética, 1457b, 6) e, nesse sentido, a figura paradigmática frente à noção de literalidade. Quando se reporta à metáfora, portanto, a tradição tem se referido aos casos em que a literalidade da linguagem está em xeque.

Devido a esse viés, é importante que se diga que estamos tratando de metáforas linguísticas. É possível extrapolar a noção de metáfora como transferência para uma coisa do nome de outra pensando a própria noção de "nome" como uma metáfora de qualquer tipo de signo não verbal. Mas não pretendemos incluir aqui esse tipo de análise. Quando falamos em metáforas estamos falando do fenômeno de não literalidade verbal, isto é, da exceção que supõe a possibilidade de uso literal da linguagem verbal. Nesse sentido, a metáfora de que tratamos diz respeito à metáfora que supõe um código estabelecido e, no caso em tela, o próprio código linguístico de uma língua natural.

Metáforas são fenômenos semânticos ou contextuais? Dizem respeito ao código ou ao uso da linguagem? Para responder a essas questões, teremos três momentos. No primeiro, discutiremos o quadro clássico que trata a metáfora como um evento pragmático. No segundo momento, trataremos da metáfora como um acontecimento que depende do código linguístico sob um viés minimalista semântico. E, por último, veremos a 
solução contextualista para o fenômeno. Ao fim do texto, esperamos ter oferecido elementos convincentes para defender que a metáfora é um caso de subdeterminação semântica em que pesam tanto aspectos contextuais quanto semânticos para a sua produção e interpretação. Desse modo, a metáfora como limite da significatividade linguística, revela as implicações profundas de teorias semânticas (que tratam das relações entre os signos e o mundo) sobre teorias da significação (que envolvem o uso social e cognitivo pelos usuários do signo linguístico).

\section{Metáforas como caso de indeterminação semântica: o velho quadro semântico-pragmático}

Tomemos o seguinte diálogo:

(1) A - Em que estado de espírito você encontrou o chefe? $B$ - O leão rugiu. ${ }^{2}$

Para que a frase do falante $B$ faça sentido na ação que está em curso, precisaríamos imaginar que $B$ está se referindo ao chefe de um modo não literal ou metafórico. Grice (2013) explora esse tipo de fenômeno a partir do que ficou conhecido como implicaturas conversacionais. Implicaturas são acarretamentos pragmáticos que não dependem stricto senso do código linguístico para garantir a troca linguística3. $\mathrm{B}$ poderia ter dito “ $\mathrm{O}$ homem está uma fera" (o que ainda é uma metáfora!4) ou "O humor do

\footnotetext{
2 O exemplo é de Levinson (1983).

3 Uma das pretensões da pragmática griceana é poder ser capaz de prever ou explicar os fenômenos nos quais o significado de uma frase não decorre do código linguístico, mas justamente de informações contextuais não disponíveis semanticamente. Ver Grice (2013) e, esquematicamente, Levinson (1983).

4 Aqui a substituição de uma metáfora por outra é emblemático. Apesar do uso de metáforas, o diálogo foi bem-sucedido. A metáfora é o "caso estranho" ou a "exceção" que leva a "pensar no geral com passionalidade". Mais à frente veremos como, segundo Bezuidenhout (2001), o sucesso de diálogos como estes em que aparecem metáforas só é possível quando saímos do
} 
chefe não está bom" e, mesmo assim, a sua resposta teria sido relevante pragmaticamente e a ação não teria sido quebrada.

Segundo o quadro semântico-pragmático padrão5 ${ }^{5}$ que postula uma divisão bem-comportada entre o que é expresso semanticamente via código linguístico e o que é acarretado pragmaticamente, a interpretação metafórica de uma frase é uma implicatura que, como tal, é indeterminada semanticamente. $\mathrm{O}$ intérprete, diante da impossibilidade de interpretar o significado do código linguístico de forma literal, procuraria uma maneira de a informação fornecida pelo interlocutor não romper a ação em curso. Esse seria o caso da frase "o leão rugiu" interpretada como dizendo respeito ao humor do chefe. Caso fosse interpretada literalmente, segundo o quadro semântico-pragmático, a resposta não faria sentido. Esse mesmo mecanismo também explicaria o significado que atribuímos a frases dos do tipo:

(2) Julieta é o sol.

(3) Os bosques estão sorrindo.

(4) As planuras atacamenhas tinham uma atmosfera marciana.

Desde o quadro semântico-pragmático, (2) seria uma metáfora pois acarretaria, por exemplo, que Julieta tem uma presença marcante. (3), por sua vez, acarretaria o estado de ânimo de alguém em um passeio de fim de tarde. E (4), por não poder estar afirmando que a atmosfera do deserto do Atacama seja, de fato, marciana, deve acarretar, entre

marco dos atos de fala indiretos (como as implicaturas conversacionais) e passamos a tratá-las como um ato de fala direto.

5 Recanati (2010) chama de "velha pintura" ou "velho quadro" a teoria da significação na qual semântica, por um lado, e pragmática, por outro, possuem papéis bem-comportados e claramente definidos. À semântica caberia o papel de explicar como se chega à proposição expressa a partir do significado convencional dos termos de um proferimento qualquer. À pragmática restaria a função de explicar como proferimentos podem pressupor ou implicar conversacionalmente algo diferente da proposição expressa. Chamamos esse quadro que se auto complementa de quadro semântico-pragmático padrão. 
outras possibilidades, que, em visitando o deserto, encontraríamos uma paisagem semelhante àquela que se esperaria ver em uma eventual visita ao planeta vermelho.

Isso aconteceria, porque, segundo o quadro semântico-pragmático padrão, o significado metafórico das frases não decorre do próprio código linguístico. Metáforas seriam tão somente atos de fala indiretos ou significados segundos. A ação em curso seria a responsável por oferecer elementos para o intérprete acarretar o significado sem que ele estivesse dado no significado literal da frase usada metaforicamente. O nível de determinação semântica da metáfora seria zero nesse quadro já que a mesma frase poderia ser interpretada em outro contexto de modo diverso e sem relação com o significado literal da frase, como ocorre, ademais, com outras implicaturas conversacionais. Veja:a:

(5) A - Tem leite na geladeira?

B - Precisamos ir ao supermercado.

Nada há na semântica da proposição expressa por B que signifique "Não há leite na geladeira". Mesmo assim, A deve acarretar tal implicatura pois, caso contrário, a afirmação de B não faria qualquer sentido. Tal acarretamento parece ser gerado de forma independente da proposição expressa por B. Mas será que a interpretação metafórica do lance de B em (1) (O leão rugiu) é também uma implicatura? Alguns elementos nos levam a crer que não.

Em primeiro lugar, essa explicação não parece justificar a relação que intuitivamente há entre o significado metafórico e o significado literal de uma frase. A frase "o leão rugiu" poderia suportar qualquer tipo de implicatura, mas não poderia suportar qualquer tipo de interpretação metafórica. Responder que "o leão rugiu" pode acarretar que não devo incomodar o chefe hoje ou que devo ser mais simpático que o normal, mas não pode significar que o chefe está calmo como um cordeiro. Ou seja, não é qualquer interpretação que vale quando estamos diante de um proferimento 
metafórico. Já uma implicatura parece poder ser gerada por virtualmente qualquer frase e eventualmente qualquer interpretação será válida, desde que mantenha a ação em curso. Dito ainda de outra forma, uma metáfora, apesar das muitas possibilidades de interpretação, enseja apenas um certo número de leituras que parecem manter algum tipo de vínculo com o significado literal, e isso não ocorre, necessariamente, com uma implicatura.

Esse vínculo entre o significado metafórico e literal de uma frase fica mais evidente quando tentamos aplicar sobre uma metáfora os mecanismos de cancelamento das implicaturas conversacionais. Para cancelar a implicatura gerada em (5), a saber, que não há mais leite na geladeira, bastaria afirmar que "Precisamos ir ao supermercado, mas tem leite, sim", ou ainda "Precisamos ir ao supermercado, depois respondo à sua pergunta”. A implicatura é cancela à revelia do significado atribuído à frase "precisamos ir ao supermercado". Uma metáfora, por outro lado, só pode ser cancelada por alguma cláusula que obrigue a interpretação literal. A interpretação metafórica gerada em (1) só pode ser cancelada quando se evoca o significado literal da frase, como quando se afirma que "o leão rugiu... do outro lado da rua enquanto eu falava com o chefe que estava calminho". Ou seja, uma metáfora, embora não corresponda ao que está expresso semanticamente, parece direcionar interpretações possíveis. Uma implicatura, por outro lado, não sofre esse tipo de determinação. Dito ainda de outra forma: uma metáfora, ao contrário de uma implicatura, parece expressar diretamente o seu significado como defendem Bezuidenhout (2001) e Reimer (2009) e, dependem, portanto, do código linguístico para a sua interpretação. Mas antes disso, vejamos a solução literalista de Stern (2000, 2009), baseada no minimalismo semântico.

\section{Metáforas determinadas semanticamente: o minimalismo semântico}

O minimalismo semântico de Cappelen e Lepore (2005), na medida em que advoga que as palavras e frases podem ser tratadas indepen- 
dentemente do contexto de proferimento, está mais alinhado ao quadro semântico-pragmático padrão e, portanto, tem uma resposta semelhante àquele quadro ao tratar do fenômeno das metáforas. Entender a base do minimalismo é fundamental para entender a solução literalista de Stern (2000, 2009) que parte do quadro minimalista e aposta na subdeterminação semântica das metáforas, tópico que trataremos a seguir.

O contexto de proferimento, segundo o minimalismo semântico, influencia o significado total apenas quando os dados contextuais são requeridos pela própria semântica da frase, independentemente da ação em curso. Para Cappelen e Lepore, "a característica mais saliente do Minimalismo Semântico é que ele admite poucas expressões sensíveis ao contexto e, portanto, reconhece um efeito muito limitado do contexto da expressão no seu conteúdo semântico" (2005, p. 2, tradução nossa). ${ }^{6}$

As expressões sensíveis mais óbvias são as comumente designadas de Conjunto Básico de Expressões Sensíveis ao Contexto: pronomes pessoais em seus casos e número, pronomes demonstrativos em seus casos e número, os advérbios de lugar ("aqui", "lá", ...) e tempo ("hoje”, "ontem", "amanhã") e os adjetivos "atual” e "presente" e outros do gênero. Segundo o minimalismo, apenas essas e algumas outras poucas palavras (como “inimigo", “amigo”, “estrangeiro”, “doméstico" etc.) possuem o gatilho para capturar informações do contexto em que foram proferidas. Dito de outra forma, apenas esses termos não possuiriam o seu significado plenamente determinado antes de serem saturadas 7 pelo contexto de

\footnotetext{
6 Do original: The most salient feature of Semantic Minimalism is that it recognizes few context sensitive expressions, and, hence, acknowledges a very limited effect of the context of utterance on the semantic content of an utterance.

7 Recanatti define "saturação" da seguinte maneira: "Saturação é um processo pragmático de atribuição de valor contextual que é acionado (e tornado obrigatório) por algo da própria frase, a saber, a expressão linguística à qual um valor é contextualmente atribuído" (Saturation is a pragmatic process of contextual value-assignment that is triggered (and made obrligatory) by something in the sentence itself, namely the linguistic expression to which a value is contextually assigned). (2010, p. 4, tradução nossa). Na frase "eu estou feliz" a expressão linguística "eu" tem seu significado preenchido contextualmente: "eu" é o indivíduo que profere a frase. Esse "preenchimento" contextual, por outro lado, é semanticamente determinado dado que é disparado pelo próprio código linguístico.
} 
proferimento. Além disso, para o minimalismo, nessas palavras aparece o único tipo de influência contextual possível na determinação da proposição semanticamente expressa por uma frase.

A tese minimalista, na medida em que se fixa na noção de proposição semanticamente expressa é, a princípio, bastante simples. Segundo Cappelen e Lepore, a proposição semanticamente expressa por um proferimento é dada apenas pelo significado literal das palavras e pela sua composição em frases, respeitando a saturação das expressões sensíveis ao contexto (quando houver). Assim, qualquer proferimento de (1) "O leão rugiu” expressa a proposição de que o leão rugiu e é apenas verdade caso o leão tenha rugido. Dada uma frase qualquer, o conteúdo semântico expresso por essa frase não deve depender de qualquer outro tipo de interpretação que não seja diretamente semântica. Isso não significa que essa frase não possa ser usada para outros fins. Mas "ser usada" não é o mesmo que "significar" segundo o minimalismo. A proposta do minimalismo é que a proposição semanticamente expressa é uma decorrência apenas do significado das palavras e de sua composição. E informações contextuais seriam capturadas exclusivamente pelo Conjunto Básico de Expressões Sensíveis ao Contexto.

Dentre as expressões do Conjunto Básico, o caso dos demonstrativos é interessante. Além de permitir compreender como funciona a saturação de um termo com informações contextuais, eles permitem compreender o passo dado por Stern e a explicação da metáfora como um caso de subdeterminação semântica. Nos demonstrativos, seguindo a tese kaplanianda endossada pelos minimalistas, além da função caráter, isto é, da regra que regula a saturação do termo sensível ao contexto, há um complemento não linguístico para assegurar a fixação da referência. Tomemos, como exemplo, a situação na qual exclamo para meu interlocutor:

(6) Estas planuras têm uma atmosfera marciana! 
Para saber a que planuras estou me referindo, o termo "estas" intuitivamente deve vir acompanhado de algum ato não linguístico, como um apontamento, que faz com que a referência agenciada pelo demonstrativo seja determinada por algum tipo de informação dada pelo contexto. Quando aponto para a paisagem e digo "estas planuras", o termo "planura", que tinha um significado fixo, passa a ser dependente do meu contexto de proferimento, ou seja, passa a ser sensível ao contexto. Ou ainda, usando a noção de designadores rígidos, o termo "planura" que era não rígido (pois poderia se referia a qualquer planura em qualquer mundo possível) passa a designar apenas a planura que atravesso no momento da ação em curso.

Para tratar desses casos, Kaplan sugere a introdução formal do operador Dthat que seria responsável justamente por isso: tornar um termo contextualmente dependente do demonstrativo. Nas palavras de Stern,

[...] Kaplan introduz um símbolo demonstrativo especial 'Dthat', que é 'completado' por uma descrição definida (não rígida) Ф. 'Dthat' tem dois efeitos. Primeiro, ele toma um termo singular $\Phi$, cujo conteúdo é um complexo de condições descritivas, e produz a referência direta descrição-dthat Dthat [Ф] cujo conteúdo é seu referente individual. Segundo, é necessário um termo singular $\Phi$ cujo caráter (assumindo que não contenha índices) é constante e produz a descrição-dthat cujo caráter não é constante na determinação de diferentes conteúdos (= referentes diretos) em diferentes contextos (STERN, 2000, p. 100, tradução nossa). ${ }^{8}$

Uma primeira interpretação de Dthat pode levar a crer que ele depende exclusivamente do ato não linguístico para funcionar. Em outras

\footnotetext{
8 Do original: Kaplan introduces a special demonstrative symbol 'Dthat', which is "completed" by a (nonrigid) definite description $\Phi$. 'Dthat' has two effects. First, it takes a singular term $\Phi$, whose content is a complex of descriptive conditions, and yields the directly referential dthat-description Dthat $[\Phi]$ whose content is its individual referent. Second, it takes a singular term $\Phi$ whose character (assuming it contains no indexicals) is constant and yields the dthat-description whose character is nonconstant determining different contents (= direct referents) in different contexts.
} 
palavras, intuitivamente identificamos o operador formal Dthat com o próprio ato não linguístico de apontamento. Todavia, isso não é o caso. $O$ fato de um demonstrativo estar relacionado a um ato não linguístico como um apontamento não implica que a dependência contextual de uma frase contendo um operador Dthat seja dada por tal apontamento. Stern indica que há casos nos quais termos demonstrativos dispensam o ato demonstrativo que fixa a sua extensão. Para o autor, "[...] existem usos não demonstrativos da palavra 'aquilo' que carecem de demonstrações - por exemplo, 'havia aquele livro de Kant sobre pura razão'" 9 (STERN, 2000, p. 77, tradução nossa). No exemplo de Stern, não é necessário apontar a Crítica da Razão Pura de Kant para que o ouvinte recupere a extensão de "aquele livro". O referente do termo é recuperado pois já faz parte da ação em curso ou do conhecimento tácito já compartilhado pelos falantes. Isso só é possível, pois os demonstrativos não dependem estritamente do ato não linguístico para funcionar. Defender o contrário seria ir contra, aliás, a própria tese minimalista que advoga que o aporte de informações contextuais é semanticamente dirigido, ou seja, um demonstrativo já deve possuir em si a regra (ou função caráter, nas palavras de Kaplan) que dispara a necessidade de saturação por informações contextuais.

Assim, para manter a coerência com a própria proposta de Stern, talvez fosse mais preciso afirmar que, em vez de usos não demonstrativos, como aparece na citação, termos demonstrativos, em certos momentos, prescindem de um ato extralinguístico para estarem completos. Isso porque um demonstrativo apenas precisa desse ato extralinguístico quando linguisticamente a referência não está assinalada. A maioria dos demonstrativos, de fato, não são seguidos de um ato extralinguístico justamente porque já possuem a sua referência contextual disponível independentemente do apontamento.

9 Do original: [...] there are nondemonstrative uses of the word "that" that lack demonstrations - for example, "there was that book by Kant on pure reason" [...]. 
Essa conclusão não é trivial. Ela implica que o operador Dthat, ao contrário do que a intuição inicial pode sugerir, tornaria o próprio termo a que se refere um designador rígido (ao torná-lo dependente do contexto de proferimento) de maneira diretamente semântica, isto é, não é o ato extralinguístico de apontamento vinculado intuitivamente aos demonstrativos que dispara uma leitura contextual do termo que está sob o escopo do demonstrativo. A própria regra que rege a interpretação do demonstrativo (ou seja, sua função caráter) é que torna o termo sensível contextualmente.

Ora, defender que os demonstrativos semanticamente levam a determinação contextual dos termos que caem sob o seu escopo está a um passo da solução de Stern ao fenômeno das metáforas. Para isso, basta que se postule a existência de um outro operador semelhante ao Dthat que obrigaria justamente a interpretação metafórica. O primeiro passo consiste em demonstrar que metáforas são sensíveis ao contexto como que regidas por um demonstrativo. O segundo passo consiste em defender ser possível introduzir um operador semântico que faria com que as expressões de uma frase se tornem insaturadas e, portanto, saturáveis contextualmente. Esta é a aposta de Stern e esse operador Stern nomeia de Mthat. Ele faz com que uma expressão qualquer em uma frase se torne semanticamente sensível ao contexto e, portanto, insere o fenômeno das metáforas no escopo da própria semântica.

\subsection{Do minimalismo ao literalismo de Stern: primeira proposta de subdeterminação semântica da metáfora}

Para o minimalismo, uma metáfora não seria determinada semanticamente. Isso porque apenas as expressões do Conjunto Básico dependem do contexto para terem os seus significados fixados e, portanto, a proposição semanticamente expressa corresponderia sempre à sua interpretação literal. Por outro lado, se o mecanismo de saturação dos demonstrativos (uma das classes de expressões do Conjunto Básico) for 
levado a sério e, eventualmente, extrapolado, abre-se a possibilidade de outras expressões além das do Conjunto Básico, em especial, as metáforas, serem tratadas dentro de uma teoria estritamente semântica. Essa é a proposta de Stern (2000, 2009). Para Stern, metáforas, assim como frases contendo demonstrativos, seriam semanticamente dependentes do contexto porque haveria um dispositivo semântico que dirigiria tal dependência. Discutir essa tese é o objetivo desta seção.

Segundo Stern, o significado de uma frase na qual aparece algo tido como uma metáfora só é possível pois há a seleção de informações que não estão dadas semanticamente na frase literal. Entretanto, para que caracteres contextuais sejam capturados pela semântica da frase e não sejam meramente decorrentes do uso da frase em um contexto, como acontece com uma implicatura conversacional, é necessário haver algum dispositivo semântico que possibilite isso. A solução de Stern poderia soar artificial se Kaplan não tivesse usado o expediente exposto acima para tratar dos demonstrativos que fazem parte do conjunto de expressões básicas determinadas contextualmente. E defender que demonstrativos são expressões contextuais é uma tese livre de qualquer suspeita, mesmo para minimalistas radicais como Cappelen e Lepore.

O dispositivo semântico que Stern propõe introduzir é análogo ao Dthat. Ambos, Dthat e o dispositivo defendido por Stern, tornariam insaturada uma expressão qualquer, tornando-a rígida e dependente do contexto de proferimento. A diferença é que, enquanto $D$ that seleciona informações relativas a lugar, posição e identidade de uma descrição definida, contextualizando-a, o operador Mthat faz com que tais descrições passem a exigir interpretação diversa da literal e, portanto, Ihe asseguraria uma interpretação metafórica.

Assim, a frase (2), poderia ser representada da seguinte forma:

(7) Julieta Mthat [é o sol]

Da mesma forma que o operador Dthat proposto por Kaplan, Mthat faria com que a expressão que cai sob o seu escopo tenha que ser satu- 
rada a partir de informações relevantes do contexto de proferimento. Justamente por isso, "ser o sol" na frase (6) teria as suas funções significativas (a função caráter, que dirige a seleção de eventuais informações contextuais, e o conteúdo, a referência efetivamente capturada pela expressão) relativizados ao contexto de proferimento. Esse predicado, então, não se referiria mais ao seu significado literal, mas às características contextualmente relevantes de Julieta compartilhadas pelos falantes em questão que podem saturar a expressão "ser o sol". Isto é, rigidamente a expressão "ser o sol" designaria, dada a presença do operador metafórico Mthat, características do sujeito sem que isso leve à suposição que Julieta seja literalmente o sol. Assim, da mesma forma que os demonstrativos, nesta leitura, o caráter da expressão "ser o sol" não precisa necessariamente de um ato extralinguístico como um apontamento.

Além disso, qualquer descrição definida, propriedade ou nome próprio pode cair sob o escopo do operador Mthat e passar a necessitar da captura de características do contexto. Justamente por isso, não apenas o predicado "ser o sol" pode ser relativizado ao contexto via operador metafórico. As seguintes formas, no que tange à frase (2), também seriam possíveis:

(7') Mthat [Julieta] é o sol.

(7") Mthat [Julieta] Mthat [é o sol]

(7'") Mthat [Julieta é o sol]

Cada uma delas representa a possibilidade de interpretação metafórica das diversas expressões que compõe a frase "Julieta é o sol". Em (7') o nome relativizado ao contexto é "Julieta". Em (7") tanto sujeito quanto predicado passam a necessitar de informações contextuais de modo a fixar a sua referência com base no caráter compartilhado pelos falantes do nome "Julieta" e da propriedade "ser o sol". Por fim, em (7"'), a expressão como um todo deve ser compreendida de forma metafórica para ter o seu significado fixado. 
Stern define o operador metafórico da seguinte forma:

\begin{abstract}
'Mthat' é um operador lexical (isto é, um operador formador de termos sobre termos) no nível da forma lógica que, quando prefixado em uma expressão (literal) $\Phi$, produz uma expressão sensível ao contexto ' $M$ that $[\Phi]$ ' cujos tokens em cada contexto $c$ expressam um conjunto de propriedades pressupostas em c para ser m(etaforicamente) associado à expressão $\Phi$, de modo que a proposição $\backslash \ldots\{[$ Mthat $[\Phi]\}$ (c)... [seja verdadeira ou falsa em uma circunstância](2009, p. 289 , tradução nossa). ${ }^{10}$
\end{abstract}

Assim, o operador Mthat possibilita, para Stern, justamente o tratamento semântico do fenômeno sem necessitar lançar mão da interpretação clássica recuperada pela tese minimalista mais radical de Cappelen e Lepore. $\mathrm{O}$ operador Mthat marca um acontecimento semântico no interior da frase. Ele marca, nas palavras do autor, "o fato de que a expressão metafórica (ou a interpretação metafórica do veículo) é sensível ao contexto (para seu parâmetro metafórico), mas também restringe o leque de possíveis interpretações que podem ser geradas contextualmente" (2013, p. 290, tradução nossa)."

Entretanto, poderíamos questionar até que ponto a solução de Stern não é apenas um artifício formal. Ao contrário dos demonstrativos nada há na frase que indique que ela deva ser interpretada metaforicamente ou literalmente. A menos que todas as expressões possuam o operador Mthat a marcar a sua possível dependência do contexto. Ora, esse seria realmente o caso. Segundo Stern,

\footnotetext{
10 Do original: 'Mthat' is a lexical operator (i.e., a term forming operator on terms) at the level of logical form which, when prefixed to a (literal) expression $\Phi$, yields a context-sensitive expression 'Mthat $[\Phi]$ ' whose tokens in each context c express a set of properties presupposed in $\mathrm{c}$ to be $\mathrm{m}$ (etaphorically)-associated with the expression $\Phi$, such that the proposition $\backslash . .$. $\{[$ Mthat $[\Phi]\}(c)$... [is either true or false at a circumstance $]$.

1 Do original: the fact that the metaphorical expression (or the metaphorical interpretation of the vehicle) is context-sensitive (to its metaphorical parameter), but it also constrains the range of possible interpretations that can be contextually generated.
} 
Para cada sequência $S$, permita que a gramática "gere" um conjunto de formas lógicas que correspondam a todas as combinações possíveis de nós terminais preenchidos por itens lexicais contendo todas as expressões Mthat (gramaticalmente) possíveis na sequência. (Entre essas formas lógicas está a (metaforicamente) simples que não contém expressões metafóricas. Você pode pensar nisso como a forma lógica literal da sequência.) Ao dizer que a gramática ou a linguagem I gera esse "conjunto de metáforas" de formas lógicas, o que queremos dizer é que o falante conhece como parte de sua competência linguística todas as (combinações de gramaticalmente) possíveis expressões metafóricas - expressões que gramaticalmente admitem interpretações metafóricas - que podem ocorrer como parte de suas expressões.(2009, p. 292 , tradução nossa). ${ }^{12}$

Segundo Stern, o operador metafórico Mthat lexicaliza todas as possíveis interpretações de qualquer expressão. Em outras palavras, o operador Mthat gera todas as possíveis interpretações sensíveis ao contexto, entre elas aquela não sensível, isto é, a expressão literal do que é dito. Assim, o operador Mthat permite tratar frases nas quais está em jogo apenas o primeiro significado das palavras que compõem a frase (o significado literal no qual o índice do operador é nulo ou com zero informações saturáveis contextualmente) ou frases nas quais o operador não é nulo e, portanto, há alguma determinação contextual do significado das expressões que compõem a frase.

\footnotetext{
12 Do original: For each string S, let the grammar "generate" a set of logical forms that correspond to every possible combination of terminal nodes filled by lexical items containing all the (grammatically) possible Mthat expressions in the string. (Among these logical forms is the (metaphorically) bare one that contains no metaphorical expressions. You can think of that as the literal logical form of the string.) In saying that one's grammar, or I-language, generates this "metaphor set" of logical forms, what we mean is that the speaker knows as part of his linguistic competence all the (combinations of grammatically) possible metaphorical expressions - expressions that grammatically admit metaphorical interpretations-that might occur as part of his utterances.
} 
Por outro lado, apesar de Stern afirmar que o falante sabe todas as possíveis expressões metafóricas que podem ser geradas a partir de uma frase, seria mais coerente dizer que o falante é capaz de lidar ou tratar todas as possíveis interpretações que podem ser geradas, seja a partir do operador Mthat com índice nulo, seja a partir do operador Mthat selecionando características contextuais e que fará com o que o falante necessite de informações contextuais para determinar o significado da frase em questão. O operador Mthat marca, portanto, a competência semântica que é necessária ao falante para interpretar corretamente a frase, seja a partir do significado estabelecido ou incluindo informações contextuais.

Outro ponto importante na proposta de Stern diz respeito ao tipo de significado que o operador Mthat gera. Se o significado literal representado pelo índice nulo do operador diz respeito ao significado gerado a partir dos primeiros significados dos termos da frase, os possíveis significados metafóricos não correspondem simplesmente a significados segundos como as implicaturas. Os significados metafóricos são restringidos e dirigidos pelos significados primeiros dos termos. Segundo Stern, portanto, não estaríamos nem diante de uma mera implicatura nem, tampouco, diante de um novo significado ou um malapropismo, isto é, o uso diverso causado por palavras de sonoridade semelhante ${ }^{13}$. O significado primeiro da frase restringe a gama de interpretações possíveis que o operador Mthat gera. Uma frase metafórica não é, portanto, indeterminada nem determinada desde um ponto de vista semântico. Ela é exatamente subdeterminada.

13 Um exemplo clássico de malapropismo: "Este menino é muito impossível!" em vez de "Este menino é muito impulsivo!". 


\section{O contextualismo: a segunda proposta de subdeterminação semântica da metáfora}

A solução minimalista de Stern $(2000,2009)$ dá conta da subdeterminação semântica da metáfora ao postular uma possibilidade semântica para garantir a variação do significado de termos e expressões que variam conforme o contexto de proferimento. O contextualismo, na medida em que, no limite, sugere que qualquer frase pode ser enriquecida ou afrouxada semanticamente, precisa mostrar, não como a semântica captura o contexto, mas como uma frase metafórica não varia aleatoriamente em interpretação como acontece com uma implicatura ou, nos termos contextualistas, como uma metáfora não é uma expressão indireta de uma proposição como acontece nos acarretamentos pragmáticos, ironias e outros fenômenos.

Para a explicação contextualista dominante, existe um equívoco no tratamento padrão do quadro semântico-pragmático no que diz respeito ao papel que teria o significado literal em uma expressão metafórica. De modo geral, seguindo a tradição do quadro semântico-pragmático, vários teóricos da metáfora assumem em maior ou menor grau, que o significado metafórico de uma expressão deve ser em alguma medida dependente do significado literal dos termos empregados. Segundo Bezuidenhout:

De acordo com uma visão amplamente adotada sobre a metáfora, as metáforas são casos em que o falante (literalmente) diz uma coisa, mas significa outra coisa. Desejo desafiar essa ideia. Argumentarei que, quando alguém pronuncia uma sentença em algum contexto pretendendo que ela seja entendida metaforicamente, expressa diretamente uma proposição, que pode potencialmente ser avaliada como verdadeira ou falsa. Essa proposição é o que é dito pelo enunciado da sentença nesse contexto. Não transmitimos significados metafóricos indiretamente, dizendo diretamente outra coisa. Uma consequência é que, ao contrário do que Searle sugere, não chegamos ao significado metafórico que o falante pretendia 
por meio de uma interpretação literal da frase que o falante pronuncia (2001, p. 156, tradução nossa). ${ }^{14}$

A proposta de Bezuidenhout consiste em tratar o fenômeno das metáforas como expressão direta da própria intenção do falante, tão direta quanto o pode ser qualquer frase dita literal. Em outras palavras, para Bezuidenhout, não há necessidade de se supor que metáforas sejam casos de expressões indiretas de proposições, como se costumava assumir no quadro semântico-pragmático que lança mão das implicaturas. Por meio de uma expressão metafórica, o falante expressaria um conteúdo que poderia ser interpretado sem recorrer necessariamente aos significados literalmente codificados pela letra da frase.

A produção e interpretação de metáforas seriam, então, casos de enriquecimento pragmático livre. Para o contextualismo, a influência do contexto de proferimento não é apenas uma questão de saturação de expressões do Conjunto Básico. Qualquer palavra ou expressão seria passível de afrouxamento ou enriquecimento sem que, para isso, fosse necessário existir um outro dispositivo semântico, como o operador Mthat, que disparasse a captura de dados contextuais. Assim, da mesma forma que um falante poderia compreender uma frase em sentido frouxo ou enriquecido, ele também seria capaz de afrouxar ou enriquecer uma expressão qualquer para produzir uma metáfora.

Imaginemos que um amigo e eu nos encontremos em uma casa, num sítio, fechada desde o inverno passado. Ao entrar na casa e abrir as primeiras janelas e venezianas para o sol entrar, iluminando a mobília

\footnotetext{
14 Do original: According to one widely held view of metaphor, metaphors are cases in which the speaker (literally) says one thing but means something else instead. I wish to challenge this idea. I will argue that when one utters a sentence in some context intending it to be understood metaphorically, one directly expresses a proposition, which can potentially be evaluated as either true or false. This proposition is what is said by the utterance of the sentence in that context. We do not convey metaphorical meanings indirectly by directly saying something else. One consequence is that, contrary to what Searle suggests, we do not arrive at the metaphorical meaning that the speaker intended via a literal interpretation of the sentence the speaker utters.
} 
agora coberta por uma camada de pó fino que insistiu em atravessar pelas frestas, digo ao meu amigo:

(8) É silencioso aqui.

O termo "silencioso" é definido literalmente como ausência de sons ou ruídos. Entretanto, nem eu nem meu amigo esperamos que, nesse contexto, esse termo signifique a ausência total de sons. Pássaros cantam do lado de fora, tábuas rangem quando andamos pela casa, o vento uiva quando atravessa a casa. Mesmo assim, a frase é avaliada por meu amigo como verdadeira pois, naquele contexto, ser silencioso funciona como um conceito que é passível de afrouxamento e significa ausência do barulho da cidade ou ausência de barulho que quebre o "clima" daquele lugar isolado. "Silencioso" nesse contexto é, para Bezuidenhout, um conceito ad hoc. Para a autora,

Esse conceito ad hoc é um constituinte da proposição que eu expresso por minha expressão [...]. É o conceito que pretendo que meu ouvinte recupere por meio de um processo pragmático de afrouxamento. O ouvinte deve usar o conteúdo semanticamente codificado da palavra "silencioso" como uma pista, juntamente com outras suposições que se manifestam mutuamente para o falante e o ouvinte no contexto, a fim de entender o-que-é-dito(2001, p. 167, tradução nossa). ${ }^{15}$

Notemos que a autora utiliza o termo "proposição" para indicar o conteúdo expresso e comunicado pela frase. Para o contextualismo não há diferença entre o conteúdo semanticamente expresso por uma

15 Do original: This ad hoc concept is a constituent of the proposition I express by my utterance [...]. It is the concept I intend my hearer to recover by a pragmatic process of loosening. The hearer must use the semantically encoded content of the word 'silent' as one clue, along with other assumptions that are mutually manifest to speaker and hearer in the context, in order to understand what-is-said. 
frase e o conteúdo comunicado quando esse último é decorrente de enriquecimento pragmático. Mas essa premissa só se sustenta porque, segundo o contextualismo, uma frase pode conter (ou até mesmo exigir que palavras sejam tratadas como) conceitos ad hoc. Importante destacar que um conceito ad hoc não é um dos diversos significados menos usuais de um termo. Desse modo, o sentido com que usei o termo "silencioso" pode nunca ter sido usado antes nem, tampouco, chegar algum dia a ser dicionarizado. Para a autora,

O conceito silencioso não é um dos significados lexicalizados da palavra em inglês «silencioso» e não há outra palavra em inglês cujo significado lexical corresponda a esse conceito. Poderíamos decidir introduzir um novo termo em nossa linguagem, cujo significado correspondesse a esse conceito. Mas não faz muito sentido fazer isso, pois é fácil expressar o conceito ad hoc simplesmente usando o conceito lexicalizado como trampolim e confiando no contexto para ajustar este significado. Além disso, se introduzirmos um termo para silencioso, por que não para todos os outros conceitos ad hoc possíveis que podem ser transmitidos por [“É silencioso aqui"] por alteração adequada do contexto? Como existem indefinidamente muitos desses conceitos, isso seria um exercício inútil (2001, p. 167, tradução nossa). ${ }^{16}$

Segundo a proposta de Bezuidenhout, na produção e interpretação de uma metáfora os mesmos dispositivos semânticos e pragmáticos seriam mobilizados. O significado de frases metafóricas seria decorrente

\footnotetext{
16 Do original: The concept silent is not one of the lexicalized meanings of the English word 'silent', and there is no other word in English whose lexical meaning corresponds to this concept. We could decide to introduce a new term into our language whose meaning corresponded to this concept. But there is not much point in doing this, as it is easy enough to express the ad hoc concept simply by using the lexicalized concept as a springboard and relying on context to fine tune one's meaning. Moreover, if we introduce a term for silent, then why not for all the other possible ad hoc concepts that can be conveyed by ["It is silent here"] by suitably altering the context? Since there are indefinitely many such concepts, this would be an exercise in futility.
} 
de processos de enriquecimento pragmático livre nos quais seus termos funcionariam como conceitos ad hoc. Desse modo, apesar de não dicionarizados, os termos e expressões "sorrir" e "ser o sol" dos exemplos (3) e (2) manteriam algumas "pistas" ou notas características dessas noções e não manteriam outras, sendo que o contexto de proferimento seria o responsável por indicar o escopo e o alcance do significado dos termos quando aparecessem em uma frase dita metafórica. Assim, a frase (2) (Julieta é o sol), quando dita por Romeu ao se referir à Julieta (que ofusca as estrelas da noite como o sol ao amanhecer), conjuntamente com os outros dados contextuais (que incluem o amor de Romeu por ela, a posição da Julieta na sacada etc.), tem o termo "sol" afrouxado em seu significado referencial, mantendo algumas características e transmitindo ao leitor a proposição de que, para Romeu, Julieta é o sol. Notemos que o significado do termo "sol" nessa frase e nesse contexto não é e nem precisa ser dicionarizado para que possamos dizer que ele expressa diretamente uma proposição. Dado que, segundo a tese do enriquecimento pragmático livre, o conceito enriquecido ou afrouxado não está para outro conceito, a solução de Bezuidenhout elimina o problema da dificuldade de paráfrase de uma metáfora. A frase "Julieta é o sol" expressa diretamente a proposição "Julieta é o sol". O significado que essa frase suscita quando usada metaforicamente pode ser explicado da mesma forma que explicamos o significado de "silencioso" na frase (8).

O mesmo acontece com a frase (3) "Os bosques estão sorrindo". Ela poderá ser interpretada metaforicamente na medida em que, no mínimo, o verbo "sorrir" funcione como um conceito ad hoc. Enquanto conceito ad hoc, o significado do termo pode ser enriquecido ou afrouxado a depender do contexto, permitindo que a frase expresse diretamente a proposição de que o bosque está sorrindo sem que com isso tenhamos que assumir que literalmente o bosque esteja sorrindo do mesmo modo que pessoas sorriem.

Isso indica que um conceito ad hoc deve ser sempre interpretado à luz do contexto de proferimento. Será o contexto de proferimento que mobilizará as determinações semânticas de "sorrir" que serão ou não 
aplicadas e quais serão ou não enriquecidas, no caso de, por exemplo, a frase "os bosques estão sorrindo" ser afirmada por alguém que finalmente pode sair de férias e visitar uma região que há muito ansiava visitar. Assim, se assumimos a tese contextualista, a resposta de Bezuidenhout consegue dar conta do fenômeno das metáforas dentro de um quadro semântico e não relegar simplesmente aos atos de fala a explicação do fenômeno. Uma metáfora, nesse sentido, não é um ato de fala indireto. Assim como frases ditas literais, frases ditas metafóricas expressam diretamente proposições e por isso devem ser tratadas dentro do quadro da semântica. Frases ditas metafóricas são subdeterminadas semanticamente e não são meros acarretamentos pragmáticos.

Por isso, a comparação da metáfora com ironias ou atos de fala indiretos é também esclarecedora. Para Searle, já no texto clássico de 1978 (SEARLE, 2013), metáforas e ironias seriam fenômenos parecidos, pois, em ambos, o significado que o falante pretende é diferente do significado literal da frase usada. Entretanto, essa explicação do fenômeno das metáforas explica metáforas como atos de fala indiretos, ou seja, dentro do quadro semântico-pragmático. Para Bezuidenhout, por outro lado, metáforas não podem ser compreendidas como atos de fala indiretos e, sequer, usando o mesmo esquema de ironias. Ela chama atenção para o fato de ironias e atos de fala indiretos poderem se sustentar em metáforas, mas metáforas não poderem ser acarretadas de atos de fala indiretos ou de ironias. A metáfora que aparece em (1) é exemplo disso. A frase "o leão rugiu" tem como implicatura que o humor do chefe não está bom e, portanto, supõe uma interpretação metafórica que toma o humor do chefe relacionando-o ao rugido de um leão. Nesse caso, um ato de fala indireto se ampara em uma metáfora que é, portanto, semanticamente direta comparada à implicatura.

O mesmo ocorreria em uma ironia. Uma ironia poderia se sustentar em uma metáfora, mas não o contrário. Imaginemos a seguinte situação. João acabara de comer quase toda a comida que tínhamos previsto para nosso encontro. Satisfeito, deitado no sofá, ele nos observa apático. Ao 
que alguém questiona se alguém mais ainda está com fome. A minha resposta, irônica, é a seguinte frase metafórica:

(9) João está morto de fome.

O que caracteriza a ironia é o fato de, por ela, se querer afirmar justamente o contrário do que se está dizendo. Neste caso, quero dizer que João não está morto de fome. Mas isso não explica, acarreta ou elimina a metáfora. Dito de outra forma, a frase metafórica é usada para expressar uma ironia e a própria explicação da ironia nem explica nem dilui a metáfora. A ironia da frase é posterior à própria metáfora. Assim como preciso supor a interpretação metafórica para, a partir dela, acarretar a implicatura, em uma ironia metafórica, preciso supor a interpretação metafórica para compreender a própria ironia. Por outro lado, uma frase irônica não consegue desencadear uma interpretação metafórica. Posso querer dizer, metaforicamente, que meus gatos são demônios por meio de uma ironia do tipo:

(10) Sim, meus bichanos são muito calminhos.

Mas somente desta frase não é possível acarretar a interpretação metafórica que eles são demônios. Poderia afirmar, por outro lado, ironicamente que eles são anjinhos com o intuito de dar a entender que eles são demônios. Mas para chegar a essa interpretação, que nem mesmo assim é garantida, eu lanço mão novamente de uma metáfora:

(11) Meus bichanos são anjinhos.

Ou seja, novamente a expressão "ser anjinho" deve ser interpretada metaforicamente para que a própria ironia tenha sucesso. Justamente por isso, para a Bezuidenhout: 
As interpretações metafóricas têm um tipo de instantaneidade (directness) que não é compartilhado por outras interpretações derivadas pragmaticamente, como casos de ironia e atos de fala indiretos. As metáforas devem ser (inicialmente) lançadas a partir de enunciados, embora, é claro, depois de alguém ser lançado no espaço metafórico, ele possa estender ou elaborar a metáfora (2001, p. 164, tradução nossa). ${ }^{17}$

Ao contrário do que se espera de um conteúdo acarretado por uma implicatura ou mesmo por uma ironia, uma metáfora tem, segundo Bezuidenhout, o mesmo tipo de expressividade direta que as frases ditas literais possuem. Assim, recorrer a atos de fala indiretos, como fazem minimalistas mais radicais ou pensadores do quadro semântico-pragmático, para explicar a metáfora, não seria uma boa estratégia. Para explicar como as metáforas são interpretadas e, no nosso caso, qual é a relação que elas possuem com o significado literal dos termos empregados na frase, seria necessário entender como as próprias frases literais funcionam e como o significado literal de uma frase é expresso. A resposta já podemos supor na medida em que, para a autora, a explicação de como o código linguístico expressa significados é contextualista. Metáforas assim como frases ditas literais, justamente por expressar diretamente o seu conteúdo, são passíveis de enriquecimento pragmático livre.

Mais explicitamente, assinala Bezuidenhout:

Chamo a minha concepção de o que é dito de uma concepção contextualista, porque permite que alguns aspectos do que é dito possam ser inteiramente determinados pragmaticamente. Ou seja, pode não haver regra sintática ou semântica que

\footnotetext{
17 Do original: Metaphorical interpretations have a kind of directness that is not shared by other pragmatically derived interpretations, such as cases of irony and indirect speech acts. Metaphors must be (initially) launched from utterances, although of course once one is launched into metaphorical space, one can extend or elaborate on the metaphor.
} 
gere esses aspectos do que é dito. Em vez disso, o falante pretende que o ouvinte use as pistas sintáticas e semânticas fornecidas, juntamente com informações não linguísticas disponíveis em seu ambiente cognitivo mútuo, para recuperar o que é dito. As pistas sintáticas e semânticas por si mesmas irão subdeterminar o que é dito (2001, p. 164-5, grifo nosso, tradução nossa)..$^{18}$

O contextualismo de Bezuidenhout não implica que todo aspecto do que é dito deva ser determinado pragmaticamente. Ainda há um algum tipo de especificidade do próprio código linguístico que pode ser mobilizado para a interpretação de uma frase. Entretanto, o significado de um termo é apenas subdeterminado pelo código. Se por um lado não é claro qual é a especificidade do código linguístico frente às outras informações (pragmáticas e cognitivas) mobilizadas durante uma ação em curso, por outro lado, para a autora, o código enquanto tal não aparece como um mero produto ou superfície de processos que poderiam ser colapsados em outros supostamente mais fundamentais. Em outras palavras, o jogo de trocas linguísticas que acontece entre os falantes de uma língua supõe não apenas que os falantes se coordenem em nível pragmático e cognitivo, mas que ambos usem e respeitem minimamente a gramática do código linguístico. Assim, se, por um lado, metáforas são produto de flexibilidade semântica, mais precisamente de enriquecimento pragmático livre, por outro lado, esse enriquecimento supõe em alguma medida um código linguístico, suas regras e léxico, que podem ser recuperados ou usados justamente para produzir o efeito metafórico.

\footnotetext{
18 Do original: I call my conception of what is said a contextualist conception, because it allows that some aspects of what is said may be entirely pragmatically determined. That is, there may be no syntactic or semantic rule that generates these aspects of what is said. Instead, the speaker intends the hearer to use the syntactic and semantic clues provided, along with non-linguistic information available in their mutual cognitive environment, in order to recover what is said. The syntactic and semantic clues by themselves will underdetermine what is said.
} 


\section{Considerações finais}

De um jeito ou de outro, tanto a solução minimalista de Stern quanto a contextualista de Bezuidenhout apostam em uma espécie de flexibilidade semântica para explicar a relação entre o significado de uma metáfora e aquele atribuído ao código linguístico em uma frase com sentido. Se aceitamos a tese de Bezuidenhout e compreendemos o fenômeno como um caso de flexibilidade semântica por conceitos ad hoc, uma metáfora é apenas subdeterminada semanticamente. É certo que o tipo de flexibilidade semântica defendida por Bezuidenhout, quando comparada à suposta por Stern, possui pressupostos diferentes. Mas a solução de ambos se aproxima por desembocar na tese da subdeterminação semântica da metáfora. ${ }^{19}$

As soluções de Stern e Bezuidenhout acerca do fenômeno das metáforas mostra que a flexibilização semântica é uma propriedade semântica. Há em qualquer frase a possiblidade de aporte de elementos contextuais desde que eles sejam requeridos ou possibilitados pelos conceitos informados semanticamente. Depois que uma frase é proferida, a ação pode seguir o seu curso e os significados segundos e as implicaturas geradas podem ser virtualmente infinitas. Ouvir alguém dizer que os bosques estão sorrindo, por exemplo, pode levar às mais diversas reações a depender da ação que já estava se desenrolando e dos agentes em questão. Pode ser um convite a olhar mais de perto o que se passa ou a suspeitar da normalidade cognitiva do nosso interlocutor. Mas a frase quando proferida no interior da ação traz um aporte semântico. Ela leva para o interior da ação em curso conceitos que são dados via código linguístico. A metáfora acontece quando a frase é interpretada de modo flexível seguindo as pistas dadas pelos conceitos.

\footnotetext{
19 É importante reiterar que isso não resolve o fato de as teorias contextualistas e minimalistas serem teoricamente incompatíveis na medida em que, ou é a semântica da frase que dirige o aporte de informações contextuais na composição final do significado de uma frase, ou é o contexto que dirige e coordena o significado de uma frase desde o princípio. Justamente por isso, fazer um curto-circuito entre estas duas posições teóricas, como o propõe em algum grau Wearing (2013), apesar de dar conta da pluralidade do fenômeno, acaba resolvendo um problema ao mesmo tempo que torna a teoria inconsistente.
} 
Por fim, a tese que chamamos de subdeterminação semântica da metáfora, que pode ser tratada tanto por um viés minimalista/literalista quando por um viés contextualista retira o fenômeno das metáforas linguísticas do interior do tratamento semântico-pragmático padrão. Metáforas não podem ser meros acarretamentos pragmáticos. Ora, ao mostrar que esse fenômeno que está nas bordas da significatividade linguística requer um tratamento semântico, acabamos por mostrar que teorias semânticas não podem se furtar de discutir aspectos de teorias do significado em sentido mais amplo, como se as segundas dissessem simplesmente respeito ao modo como usamos a linguagem sem qualquer vínculo com as estruturas semânticas de uma língua. Ao mostrar que as metáforas são fenômenos linguísticos contextuais que dependem do código linguístico para ser interpretadas e gerar atos de fala indiretos, acabamos por mostrar que uma teoria semântica deve ser capaz de tratar de alguns aspectos ontológicos e epistemológicos que mobilizam uma eventual teoria do significado.

\section{Referências}

ARISTÓTELES. Poética. Tradução de Eudoro de Souza. São Paulo: Abril Cultural, 1984.

BEZUIDENHOUT, A. Metaphor and what is said: a defense of a direct expression view of metaphor. Midwest Studies in Philosophy, 25, p. 156-186, 2001. https://doi.org/10.1111/1475-4975.00044

BLACK, M. Models and Metaphors. Ithaca: Cornell University Press, 1962.

BORG, E. Minimal semantics. Oxford: Oxford University Press, 2004. https:// doi.org/10.1093/0199270252.001.0001

CAPPELEN, H. LEPORE, E. Insensitive semantics: a defense of semantic minimalism and speech act pluralism. Malden/Oxford: Blackwell Publishing, 2005. https://doi.org/10.1002/9780470755792

EZCURDIA, M. STAINTON, R. J. The semantics-pragmatics boundary in philosophy. Peterborough: Broadview press, 2013. 
GRICE, H. P. Logic and conversation. In: GRICE, H. P. The semantics-pragmatics boundary in philosophy. Peterborough: Broadview press, 2013. p. 47-59.

KAPLAN, D. Demonstratives: an essay on the semantics, logic, metaphysics, and epistemology of demonstratives and other indexicals. In: ALMOG, J.; PERRY, J.; WETTSTEIN, H. (ed.). Themes from Kaplan. New York: Oxford Univesity Press, 1989. p. 481-563.

LAKOFF, G. \& JOHNSON, M. Metaphors we live by. Chicago: The University of Chicago, 1980.

LEVINSON, S. Pragmática. Tradução Luiz Carlos Borges e Aníbal Mari. São Paulo: Martins Fontes, 2007.

LEVINSON, S. Pragmatics. Cambridge: Cambridge University Press, 1983.

LEWIS, D. General Semantics, Synthese, 22(1-2), p. 18-67, 1970. https://doi. org/10.1007/BFo0 413598

PERINI-SANTOS, E. Contextualismo. Compêndio em linha de problemas de filosofia analítica, p. 1-28, 2014.

PERRY, J. The problem of essential indexical and other essays. Stanford: CSLI Publications, 2000.

RECANATI, F. Truth-Conditional Pragmatics. Oxford: Oxford University Press, 2010. https://doi.org/10.1093/acprof:0so/9780199226993.001.0001

REIMER, M. The direct expression of metaphorical content. In: STAINTON R. J. VIGER, C. (ed.). Compositionality, context and semantic values, Springer Science+Business Media B.V, p. 237-253, 2009. https://doi.org/10.1007/9781-4020-8310-5_10

SEARLE, J. Metaphor. In: Ortony, A. Metaphor and Thought. Cambridge: Cambridge University Press, 1979.

SPERBER, D. \& WILSON, D. Relevance: communication and cognition. 2. ed. Oxford: Blackwell, 1995.

STERN, J. Metaphor and minimalism. Springer, Science+business Media B.V, p. 273-298, 2009. https://doi.org/10.1007/s11098-009-9486-3

STERN, J. Metaphor in Context. Cambridge, The MIT Press, 2000.

WEARING, C. Metaphor and what is said. In: EZCURDIA, M. STAINTON, R. J. The semantics-pragmatics boundary in philosophy. Peterborough: Broadview press, 2013. p. 492-510. 
VERITAS | PORTO ALEGRE | V. 64, N. 3, JUL.-SET. 2019 | e-34859

\section{Endereço postal}

Servidão Esther Gonçalves, 175,

Bairro Rio Vermelho, CEP 88060-160,

Florianópolis SC. 